\title{
Recherche
}

\section{Impact of a patient decision aid on care among patients with nonvalvular atrial fibrillation: a cluster randomized trial}

\author{
Finlay A. McAlister, Malcolm Man-Son-Hing, Sharon E. Straus, William A. Ghali, \\ David Anderson, Sumit R. Majumdar, Paul Gibson, Jafna L. Cox, Miriam Fradette, \\ for the Decision Aid in Atrial Fibrillation (DAAFI) Investigators
}

\section{Abstract}

Background: Too few patients with nonvalvular atrial fibrillation (NVAF) receive appropriate antithrombotic therapy. We tested the short-term (primary outcome) and long-term (secondary outcome) effect of a patient decision aid on the appropriateness of antithrombotic therapy among patients with NVAF.

Methods: We conducted a cluster randomized trial with blinded outcome assessment involving 434 NVAF patients from 102 community-based primary care practices. Patients in the intervention group received a self-administered booklet and audiotape decision aid tailored to their personal stroke risk profile. Patients in the control group received usual care. The primary outcome measure was change in antithrombotic therapy at 3 months. Appropriateness of therapy was defined using the American College of Chest Physicians (ACCP) recommendations.

Results: The mean patient age was 72 years, and the median duration of NVAF was 5 years. In the control group, there was a 3\% decrease over 3 months in the number of patients receiving therapy appropriate to their risk of stroke $(40 \%$ [85/215] at baseline v. 37\% [79/215] at 3 months). In the intervention group, the number of patients receiving therapy appropriate to their stroke risk increased by $9 \%(32 \%$ [69/219] at baseline $v$. $41 \%$ [89/219] at 3 months). Although the proportion of patients whose therapy met the ACCP treatment recommendations did not differ between study arms at baseline $(p=0.11)$ or 3 months $(p=0.44)$, there was a $12 \%$ absolute improvement in the number of patients receiving appropriate care in the intervention group compared with the control group at 3 months ( $p$ $=0.03)$. The beneficial effect of the decision aid did not persist ( $p=0.44$ for differences between study arms after 12 months).

Interpretation: There was short-term improvement in the appropriateness of antithrombotic care among patients with NVAF who were exposed to a decision aid, but the improvement did not persist.

CMAJ 2005;173(5):496-501

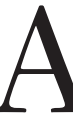

trial fibrillation affects over 2 million adults in North America, and the annual risk of stroke in the average patient with nonvalvular atrial fibrillation (NVAF) is about $5 \% .{ }^{1}$ Despite robust evidence that warfarin ${ }^{2}$ and, to a lesser extent, $\mathrm{ASA}^{3}$ are efficacious in preventing stroke among patients with NVAF and that both agents are effective and safe in clinical practice, ${ }^{4}$ these therapies are prescribed for only a minority of eligible patients. ${ }^{4,5}$

There are many reasons for this care gap, of which knowledge deficits are key: both patients and clinicians underestimate the benefits and overestimate the risks of anticoagulation therapy for NVAF., ${ }^{5,6}$ Informing patients with decision aids may be a means by which evidence is transmitted to primary care physicians and shared decisionmaking is facilitated, which is of particular relevance for conditions such as NVAF in which initiation of and adherence to therapy are highly sensitive to individual preferences. ${ }^{6,7}$ No trials have examined the impact of decision aids on the quality of care for chronic conditions such as atrial fibrillation. ${ }^{8}$

Thus, we sought to determine whether a decision aid for patients with NVAF can improve the quality of care, an end point that incorporates both physician prescribing and patient adherence.

\section{Methods}

The DAAFI Trial protocol, including copies of the various questionnaires we employed, has been published. ${ }^{9}$ The decision aid consists of a booklet and audiotape that are designed to be self-administered by patients at home (see www.canadianstroke network.ca/research/clinicians.php for an electronic copy of the booklet). The booklet describes the potential consequences of NVAF-associated stroke or transient ischemic attack, provides patient-specific estimates of stroke risk (derived from the risk stratification in the 2001 American College of Chest Physicians

Patient decision aids are distinct from general patient educational pamphlets in their focus on the benefits and risks of therapies (with explicit discussion of the probability and consequences of clinically important outcomes), their tailoring of information to the particular patient's clinical risk profile, and their emphasis on choice and shared decision-making. 
$[\mathrm{ACCP}]$ recommendations for antithrombotic therapy), ${ }^{1}$ and illustrates the potential benefits and risks of warfarin and ASA associated with each patient's baseline risk.

We employed cluster randomization at the level of the primary care practice to minimize contamination; randomization was done centrally to preserve allocation concealment using a computergenerated sequence. Although patients and their physicians were not blinded to group allocation, the outcome assessors were.

All adult patients with NVAF (diagnosed by their physician and confirmed by electrocardiogram) who were not living in an institution and had no other indication for or a contraindication to warfarin or ASA were identified in participating practices. Those who agreed to being approached by study personnel were invited to attend a standardized group tutorial about NVAF and screened for eligibility. Eligible patients who consented to enroll were randomly assigned to the intervention (the self-administered antithrombotic therapy decision aid) or to usual care. Follow-up in both arms of the trial was identical, and the primary outcome was assessed by telephone follow-up with patients and review of their medical, pharmacy and laboratory records.

The primary outcome was the change in the proportion of patients taking antithrombotic therapy deemed appropriate to their risk of stroke 3 months after the intervention: appropriate therapy was defined using the ACCP recommendations in which ASA is recommended for patients with an annual risk of stroke of $2 \%$ or less and warfarin is recommended for patients with an annual risk of stroke of more than $2 \%$ (Table 1). ${ }^{1}$ Given the lack of a widely accepted criterion for how often a patient taking warfarin should be within therapeutic range for the therapy to be deemed appropriate, we used the proportion of time in range in the trials proving the efficacy of warfarin (at least 67\% of international normalized ratios [INRs] between 2 and 3) as our primary definition and used alternate definitions in 2 sensitivity analyses. In the first analysis, we defined therapy as appropriate when patients taking warfarin had at least 1 INR measured per month and the average INR was between 2 and 3. In the second, we compared means in both study arms after calculating the proportion of time each patient taking warfarin spent with an INR measurement between 2 and 3 using the Rosendaal method (in which INR-specific person-time is calculated by incorporating the frequency of INR measurements and their actual values, and assuming that changes between consecutive INR measurements are linear over time). ${ }^{10}$

We chose a 3-month period as our primary outcome to allow comparison with other studies of decision aids and quality improvement initiatives. Secondary outcomes included knowledge about stroke and bleeding risks, expectations for antithrombotic therapy, and decisional conflict (uncertainty about which therapy to choose and evaluation of the factors contributing to the uncertainty), all of which were assessed using previously validated questionnaires. ' To examine the persistence of any effects over time, we also analyzed the proportion of patients taking appropriate therapy at 12 months as a secondary outcome.

All analyses were based on the intention-to-treat principle with the $p$ value set at 0.05 . Although the unit of allocation was the physician practice, the unit of causal inference and analysis was the patient. For the 3-month primary outcome (and the 12month secondary outcome), we report the proportion of patients in each arm whose therapy met the ACCP recommendations and calculate the mean change from baseline for each study arm, using a 2 -sample $t$ test to compare differences. This approach accounts for the possibility of differences in appropriate therapy at baseline and the possibility that the quality of care might actually decrease over time.

Because there was an imbalance in antithrombotic prescribing rates at baseline between intervention and control arms, we undertook a post hoc analysis using multivariate logistic regression and generalized estimating equations. ${ }^{11}$ This allowed us to simultaneously control these analyses for baseline rates of appropriate therapy and for the potential lack of statistical independence among study patients within the same practice.

Ethics approval was obtained from the University of Alberta Health Research Ethics Board and from the research ethics boards of each participating university.

\section{Table 1: Stratification of stroke risk at baseline}

\begin{tabular}{|c|c|c|c|c|c|}
\hline \multirow[b]{2}{*}{ Strata } & \multirow[b]{2}{*}{$\begin{array}{l}\text { Annual } \\
\text { stroke risk }\end{array}$} & \multirow[b]{2}{*}{ Clinical factors } & \multirow{2}{*}{$\begin{array}{l}2001 \text { ACCP }^{-} \\
\text {recommended } \\
\text { therapy }^{1}\end{array}$} & \multicolumn{2}{|c|}{ Group; no. of patients } \\
\hline & & & & $\begin{array}{c}\text { Decision aid } \\
n=219\end{array}$ & $\begin{array}{l}\text { Usual care } \\
n=215\end{array}$ \\
\hline Low & $1 \%$ & $\begin{array}{l}\text { Age }<65 \text { yr without hypertension, } \\
\text { reduced LVEF or prior emboli }\end{array}$ & ASA & 16 & 20 \\
\hline Moderate-low & $2 \%$ & $\begin{array}{l}\text { Age } 65-75 \text { yr without hypertension, } \\
\text { reduced LVEF, prior emboli, diabetes } \\
\text { mellitus or coronary artery disease }\end{array}$ & ASA or warfarin & 20 & 18 \\
\hline Moderate-high & $3 \%$ & $\begin{array}{l}\text { Age } 65-75 \text { yr without hypertension, } \\
\text { reduced LVEF or prior emboli, but } \\
\text { with diabetes mellitus or coronary } \\
\text { artery disease }\end{array}$ & Warfarin & 7 & 7 \\
\hline High & $6 \%$ & $\begin{array}{l}\text { Age } \leq 75 \text { yr with hypertension or } \\
\text { reduced LVEF OR age }>75 \mathrm{yr} \\
\text { without hypertension, reduced LVEF } \\
\text { or prior emboli }\end{array}$ & Warfarin & 87 & 81 \\
\hline Very high & $10 \%$ & $\begin{array}{l}\text { Age }>75 \text { yr with hypertension or } \\
\text { reduced LVEF OR any age with prior } \\
\text { emboli }\end{array}$ & Warfarin & 89 & 89 \\
\hline
\end{tabular}

Note: $\mathrm{ACCP}=$ American College of Chest Physicians, $\mathrm{LVEF}=$ left ventricular ejection fraction. 


\section{Results}

A total of 998 adult patients with NVAF not living in institutions were identified in 102 primary care practices; after screening, 446 eligible patients consented to participate (Fig. 1). A total of 219 patients in the intervention group and 215 patients in the control group were evaluated at 3-month follow-up.

There was no significant difference in baseline characteristics between the 2 groups (Table 1, Table 2): most patients at high risk of stroke and were taking or had previously taken warfarin. Almost two-thirds of trial participants expressed a willingness to re-evaluate their therapy (Table 2). One-third expressed a preference for decision-making shared between the patient and physician, and $46 \%$ felt that "the physician should primarily make the choice while taking into account my values."

Two weeks after the intervention, patients randomly assigned to the decision aid were better informed, reported less decisional conflict and were more realistic in their estimates of the potential benefits and risks of warfarin and ASA than patients receiving usual care (Table 3).

The proportion of patients whose therapy met the ACCP treatment recommendations did not differ between study arms at baseline, 3 months or 12 months (Table 4). However, there was a $3 \%$ decrease over 3 months in the number of patients in the usual-care group receiving therapy appropriate to their risk of stroke and a $9 \%$ increase in the number of patients in the intervention group receiving therapy appropriate to their stroke risk - thus, the decision aid was associated with a statistically significant $12 \%$ absolute improvement (34\% relative improvement) in the number of patients receiving appropriate care in the intervention group compared with the control group at 3

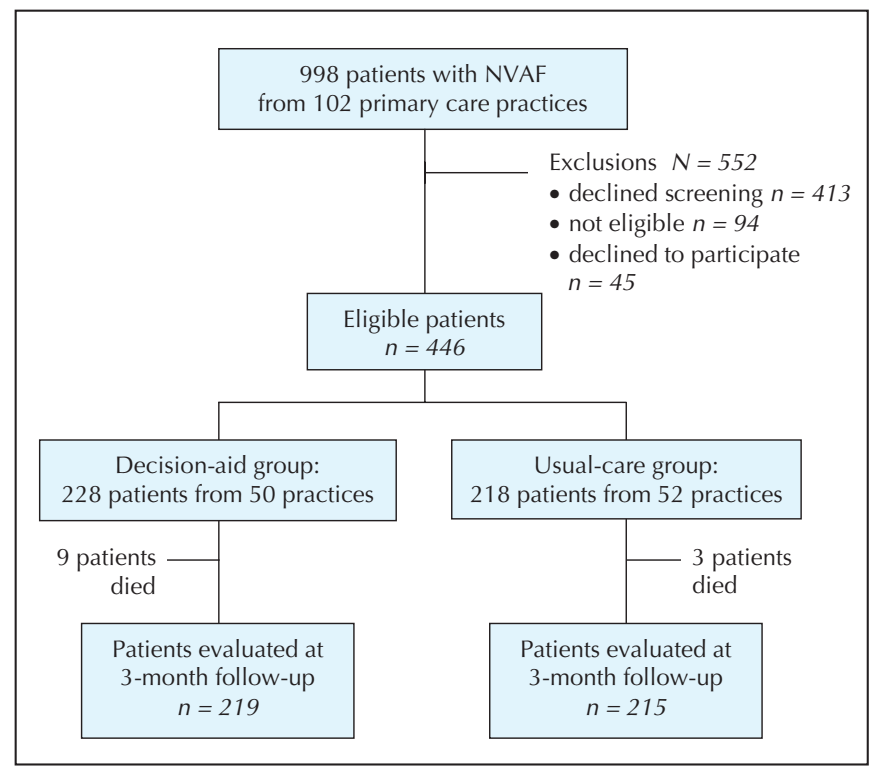

Fig. 1: Flow of patients through the trial. NVAF = nonvalvular atrial fibrillation. months $(p=0.03)$. The validity of our a priori analytic approach was borne out by how small the actual design effect was in our trial: the average cluster size was 4.3 and the intraclass correlation coefficient for antithrombotic prescribing was only 0.02 at 3 months. The results of the post hoc sensitivity analysis that adjusted for between-group differences in antithrombotic prescribing at baseline and the possibility of physician-level clustering of outcomes were consistent in direction and magnitude with the results of our prespecified analytic plan (adjusted odds ratio [OR] $1.33,95 \%$ confidence interval $[\mathrm{CI}] 0.88-2.01, p=0.18$ ).

Our findings were also robust to different definitions of "appropriate therapy." For example, when appropriate therapy among patients taking warfarin was defined as average INR between 2 and 3 plus at least monthly INR monitoring, there was a $19 \%$ absolute improvement in the number of patients in the intervention group receiving appropriate care compared with the control group $(p=0.004)$.

\section{Table 2: Baseline characteristics of study participants}

\begin{tabular}{|c|c|c|}
\hline \multirow[b]{2}{*}{ Characteristic } & \multicolumn{2}{|c|}{ Group; no. (\%)* } \\
\hline & $\begin{array}{c}\text { Decision aid } \\
n=219\end{array}$ & $\begin{array}{l}\text { Usual care } \\
n=215\end{array}$ \\
\hline Age, mean, yr (SD) & 73 (9) & $71(10)$ \\
\hline Female & $95(43)$ & $74(34)$ \\
\hline Completed high school & $84(38)$ & $72(33)$ \\
\hline \multicolumn{3}{|l|}{ Type of atrial fibrillation } \\
\hline Chronic & $112(51)$ & $113(53)$ \\
\hline Paroxysmal & $92(42)$ & $74(34)$ \\
\hline Unknown or not specified & 15 (7) & $28(13)$ \\
\hline Symptomatic & $114(52)$ & $106(49)$ \\
\hline Duration, yr (median, IQR) & $5 \quad(7)$ & $6(7)$ \\
\hline \multicolumn{3}{|l|}{ Other stroke risk factors } \\
\hline Hypertension & $124(57)$ & $117(54)$ \\
\hline Heart failure & $45(20)$ & $42(20)$ \\
\hline Diabetes mellitus & $41(19)$ & $37(17)$ \\
\hline Coronary artery disease & $70(32)$ & $67(31)$ \\
\hline $\begin{array}{l}\text { Prior stroke, transient ischemic } \\
\text { attack, or systemic arterial emboli }\end{array}$ & $48(22)$ & $47(22)$ \\
\hline Has taken warfarin in the past & $206(94)$ & $201(93)$ \\
\hline \multicolumn{3}{|l|}{ Antithrombotic therapy at baseline } \\
\hline None & $4(2)$ & $5(2)$ \\
\hline ASA alone & $20(9)$ & 18 (8) \\
\hline Warfarin alone & $168(77)$ & $174(81)$ \\
\hline Warfarin and ASA & $27(12)$ & 18 (8) \\
\hline \multicolumn{3}{|l|}{ Readiness to change } \\
\hline $\begin{array}{l}\text { Unwilling to consider changing } \\
\text { therapy }\end{array}$ & $89(41)$ & $78(36)$ \\
\hline Decision-making preference & $n=211$ & $n=176$ \\
\hline $\begin{array}{l}\text { Physician should make the } \\
\text { decision }\end{array}$ & $114(52)$ & $86(40)$ \\
\hline $\begin{array}{l}\text { Physician and patient should share } \\
\text { the decision-making }\end{array}$ & $79(36)$ & $69(32)$ \\
\hline Patient should make the decision & $18 \quad(8)$ & $21(10)$ \\
\hline
\end{tabular}

Note: $\mathrm{SD}=$ standard deviation, $\mathrm{IQR}=$ interquartile range *Unless stated otherwise. 
Using the Rosendaal method to compare INR control among patients taking warfarin in each study arm revealed that control deteriorated in the usual-care arm (INRs were between 2 and 3 on $66 \%$ of days at 3 months v. $70 \%$ of days at baseline) but improved in the intervention arm (INRs were between 2 and 3 on $72 \%$ of days at 3 months $v$. $65 \%$ of days at baseline). The between-group difference was statistically significant $(p=0.02)$.

However, by 12 months, care in both study arms had regressed toward baseline levels (Table 4), and there was no longer a statistically significant difference in the numbers of intervention and control patients receiving appropriate care ( $p=0.44$ adjusted for clusters). The strongest predictor of appropriate antithrombotic therapy at 12 months was being on that therapy at baseline (OR 3.58, 95\% CI 2.36-5.44; $p<0.001$ ).

\section{Interpretation}

Patients with NVAF exposed to an antithrombotic therapy decision aid were significantly more knowledgeable and more realistic in estimating the potential benefits and risks of therapy than control patients. These differences are all the more striking since our study participants had longstanding NVAF and our control patients received more education about NVAF than is typical in clinical practice (all potential trial participants attended a group tutorial session before enrollment). Further, a self-administered antithrombotic therapy decision aid for patients with NVAF improved the quality of their stroke prevention therapy in the first 3 months after exposure, although the effects were no longer evident by 12 months. The observed absolute difference of $12 \%$ between intervention and control patients receiving appropriate therapy after 3 months exceeds the $10 \%$ threshold frequently cited as the minimal clinically important difference in studies of quality improvement interventions. ${ }^{9}$

Our results are compatible with those of other decisionaid trials. For example, all 9 trials evaluating knowledge have shown that decision aids significantly improve patient knowledge, with a weighted mean difference of $19 \%$ (compared with $16 \%$ in this trial) ${ }^{8,12-20}$ Similarly, all 6 of the trials that examined decisional conflict reported statistically significant improvements with decision aids of magnitudes virtually identical to our results. . $^{17,18,21-24}$ However, decision aids have had variable impacts on management in the 3 tri-

\section{Table 3: Patient knowledge, expectations and decisional conflict 2 weeks after the} intervention

\begin{tabular}{|c|c|c|c|}
\hline \multirow[b]{2}{*}{ Variable } & \multicolumn{2}{|c|}{ Group; mean $(\mathrm{SD})^{*}$} & \multirow[b]{2}{*}{$p$ value } \\
\hline & $\begin{array}{l}\text { Decision aid } \\
n=219\end{array}$ & $\begin{array}{l}\text { Usual care } \\
n=215\end{array}$ & \\
\hline \multicolumn{4}{|l|}{ Knowledge and expectations } \\
\hline \multicolumn{4}{|l|}{$\begin{array}{l}\text { Mean estimate of personal biannual stroke risk } \\
\text { without treatment, \% (SD) }\end{array}$} \\
\hline Low-risk patients & $2.6 \quad(2.3)$ & $6.6 \quad(7.7)$ & 0.07 \\
\hline Moderate-risk patients & $11.3(21.1)$ & $11.7(12.0)$ & 0.95 \\
\hline High-risk patients & $12.9(11.9)$ & $17.1(17.3)$ & 0.09 \\
\hline Very-high-risk patients & $15.3 \quad(8.5)$ & $20.6(18.2)$ & 0.03 \\
\hline $\begin{array}{l}\text { Estimated their RRR with warfarin to be between } \\
60 \% \text { and } 75 \% \text {, no }(\%)\end{array}$ & $\begin{aligned} n & =187 \\
71 & (38)\end{aligned}$ & $\begin{array}{rr}n & =165 \\
32 & (19)\end{array}$ & 0.001 \\
\hline $\begin{array}{l}\text { Estimated their RRR with ASA to be between } \\
20 \% \text { and } 30 \% \text {, no. }(\%)\end{array}$ & $\begin{array}{r}n=187 \\
68 \quad(36)\end{array}$ & $\begin{array}{r}n=165 \\
22 \quad(13)\end{array}$ & $<0.001$ \\
\hline $\begin{array}{l}\text { Mean estimate of the biannual bleeding risk with } \\
\text { warfarin }\end{array}$ & $6(9.8)$ & $8.2 \quad(9.1)$ & 0.03 \\
\hline $\begin{array}{l}\text { Mean estimate of the biannual bleeding risk with } \\
\text { ASA }\end{array}$ & $4(7.8)$ & $11.1(14.6)$ & $<0.001$ \\
\hline \multicolumn{4}{|l|}{ Decisional conflict } \\
\hline Total Decisional Conflict Scale score† & $1.6(0.5)$ & $1.7 \quad(0.5)$ & 0.05 \\
\hline \multicolumn{4}{|l|}{ Subscales } \\
\hline Uncertainty & $1.8(0.8)$ & $1.7 \quad(0.7)$ & 0.02 \\
\hline Uninformed & $1.6(0.5)$ & $1.8 \quad(0.6)$ & $<0.001$ \\
\hline Unclear values & $1.6(0.5)$ & $1.7 \quad(0.6)$ & 0.04 \\
\hline Unsupported & $1.6(0.6)$ & $1.6 \quad(0.6)$ & 0.41 \\
\hline Ineffective decision-making & $1.6(0.5)$ & $1.7 \quad(0.6)$ & 0.09 \\
\hline
\end{tabular}

Note: $\mathrm{SD}=$ standard deviation, $\mathrm{RRR}=$ relative risk reduction

*Unless stated otherwise.

†The Decisional Conflict Scale measures patients' uncertainty about which therapy to choose and ranges from 1 (low conflict) to 5 (high conflict). 
als evaluating medical therapies: one ${ }^{24}$ reported a $76 \%$ increase in hepatitis B vaccination with a decision aid, another ${ }^{25}$ reported a nonsignificant $8 \%$ reduction in hormone replacement use, and the third ${ }^{17}$ reported a nonsignificant $6 \%$ increase in ASA use among patients with NVAF at low risk of stroke. Further, the appropriateness of antithrombotic therapy at baseline in our trial is consistent with data from other studies in NVAF. ${ }^{4,5,26}$

We have shown that the antithrombotic therapy decision aid we tested can lead to short-term improvements in quality of care of a magnitude similar to that of the benefits reported for specialized anticoagulation clinics. ${ }^{26}$ Of note, most quality improvement studies tend to be short-term, and thus the intervention we tested meets the current definition of a successful quality improvement tool. ${ }^{27}$ However, we believe our results emphasize the importance of including longer follow-up in quality improvement studies.

There are some limitations to our trial. The more obvious limitations (most of the trial participants had NVAF for a long time and had previous exposure to antithrombotic therapy, and the control arm received more education than is usual in clinical practice) would bias toward the null and should have reduced the short-term impact of the decision aid. Thus, neither reduce the validity of our findings that the decision aid improved the quality of care in the short term. Although it would clearly be preferable to target NVAF patients at the time of initial diagnosis, when they would presumably be most open to information-based strategies, the incidence rate in our participating practices was sufficiently low that this was not a feasible recruitment strategy. We chose a process measure (appropriate antithrombotic therapy) as our primary outcome rather than a clinical event since process measures are more sensitive indicators of improved quality - a trial powered to detect differences in rates of stroke or hemorrhage would require several thousand subjects followed for several years. Although we did not collect data on resource use by our trial patients, an earlier study of this decision aid found no difference in length of clinic visits between intervention and control patients. ${ }^{17}$ Although the develop-

\begin{tabular}{|c|c|c|c|}
\hline \multirow[b]{2}{*}{ Timepoint } & \multicolumn{2}{|c|}{ Group; no. (\%) } & \multirow[b]{2}{*}{$p$ value* } \\
\hline & $\begin{array}{c}\text { Decision aid } \\
n=219\end{array}$ & $\begin{array}{l}\text { Usual care } \\
n=215\end{array}$ & \\
\hline At baseline & $69(31.5)$ & $85(39.5)$ & 0.11 \\
\hline At $3 \mathrm{mo}$ & 89 (40.6) & $79(36.7)$ & 0.44 \\
\hline $\begin{array}{l}\text { Absolute difference between } \\
\text { baseline and } 3 \mathrm{mo}, \%\end{array}$ & 9.1 & -2.8 & 0.03 \\
\hline At $12 \mathrm{mo}$ & $70(32.0)$ & $80(37.2)$ & 0.29 \\
\hline $\begin{array}{l}\text { Absolute difference between } \\
\text { baseline and } 12 \mathrm{mo}, \%\end{array}$ & 0.5 & -2.3 & 0.44 \\
\hline
\end{tabular}

*All $p$ values are adjusted for cluster randomization. ment of newer antithrombotic options for NVAF patients may seem to obviate the need for a decision aid explaining the benefits and risks of warfarin and ASA, our decision aid can be easily adapted to include a section on other agents in the future. Finally, recognizing the substantial heterogeneity in individual preferences for NVAF therapies ${ }^{28}$ we acknowledge that concurrence with the ACCP recommendations may not be the "gold standard" by which to judge quality of care.

In conclusion, we have demonstrated that an antithrombotic therapy decision aid was well accepted by patients with NVAF, and those who received the decision aid were more informed and realistic in their treatment expectations, experienced less decisional conflict, and demonstrated statistically and clinically significant improvements in the appropriateness of their antithrombotic therapy at 3 months. However, the beneficial impact on quality of care did not persist over the long term. The challenge now is to find ways in which the initial improvements in quality of care brought about by exposure to the decision aid may be maintained for better long-term management of NVAF.

This article has been peer reviewed.

From the Division of General Internal Medicine (McAlister, Majumdar) and the Epidemiology Coordinating and Research Centre, University of Alberta, Edmonton, Alta. (Fradette); the Elisabeth Bruyere Research Institute and Division of Geriatric Medicine, University of Ottawa, Ottawa, Ont. (Man-Son-Hing); the Divisions of Geriatric and of General Internal Medicine, University of Toronto, Toronto, Ont. (Straus); the Department of General Internal Medicine, University of Calgary, Calgary, Alta. (Ghali, Gibson); and the Department of Medicine, Dalhousie University, and Capital Health, Halifax, NS (Anderson, Cox)

Competing interests: None declared.

Contributors: Finlay McAlister and Malcolm Man-Son-Hing conceived and designed the study. Miriam Fradette, as the study coordinator, and Finlay McAlister, Malcolm Man-Son-Hing, Sharon Straus, William Ghali, Paul Gibson, David Anderson and Jafna Cox, as the principal investigators at each participating site, were responsible for the acquisition of data. Sumit Majumdar contributed statistical expertise to the analysis of data. Finlay McAlister wrote the first and subsequent drafts of the manuscript. All of the authors revised the manuscript critically for important intellectual content and read and approved the final version.

Acknowledgements: We thank the primary care practices and patients who participated in the trial and Drs. Annette O'Connor and George Wells for their input in early discussions about the trial design. (A full list of all participating primary care practitioners is available at www.biomedcentral.com/qc/1471-2261/4/5.) Drs. David Sackett, Koon Teo and Andreas Laupacis provided advice on the development of the protocol and the conduct of the study, and reviewed the blinded study results.

The DAAFI Trial was funded by the Canadian Stroke Network, the Alberta Heritage Foundation for Medical Research (AHFMR), and the University Hospital Foundation, Edmonton. The following investigators hold career salary support: Finlay A. McAlister (from the AHFMR, the Canadian Institutes of Health Research [CIHR], and the University of Alberta/Merck Frosst/Aventis Chair in Patient Health Management), Sharon E. Straus (from the Ontario Ministry of Health), William A. Ghali (from the AHFMR and the Canada Research Chairs), Sumit R. Majumdar (from the AHFMR and the CIHR), and Jafna L. Cox (from the CIHR/Regional Partnership Program and the Faculty of Medicine, Dalhousie University).

\section{References}

1. Albers GW, Dalen JE, Laupacis A, Manning WJ, Petersen P, Singer DE. Antithrombotic therapy in atrial fibrillation. Chest 2001;119(Suppl):194S-206S.

2. Hart RG, Benavente O, McBride R, Pearce LA. Antithrombotic therapy to prevent stroke in patients with atrial fibrillation: a meta-analysis. Ann Intern Med 1999;131:492-501.

3. Van Walraven C, Hart RG, Singer DE, Laupacis A, Connolly S, Petersen P, et al. Oral anticoagulants vs aspirin in nonvalvular atrial fibrillation: An individual patient meta-analysis. FAMA 2002;288:2441-8. 
4. Go AS, Hylek EM, Chang Y, Phillips KA, Henault LE, Capra AM, et al. Anticoagulation therapy for stroke prevention in atrial fibrillation. How well do randomized trials translate into clinical practice? $7 A M A$ 2003;290:2685-92

5. Bungard TJ, Ghali WA, Teo K, McAlister FA, Tsuyuki RT. Why do patients with atrial fibrillation not receive warfarin? Arch Intern Med 2000;160:41-6.

6. McAlister FA. Atrial fibrillation, shared decision making, and the prevention of stroke. Stroke 2002;33:243-4

7. Barry MJ. Health decision aids to facilitate shared decision making in office practice. Ann Intern Med 2002;136:127-35.

8. O'Connor AM, Stacey D, Entwistle V, Llewellyn-Thomas H, Rovner D, Holmes-Rovner M, et al. Decision aids for people facing health treatment or screening decisions [Cochrane review]. In: The Cochrane Library; Issue 1, 2004. Oxford: Update Software.

9. McAlister FA, Man-Son-Hing M, Straus SE, Ghali WA, Gibson P, Anderson $\mathrm{D}$, et al. A randomized trial to assess the impact of an antithrombotic decision aid in patients with nonvalvular atrial fibrillation: The DAAFI Trial Protocol [ISRCTN14429643]. BMC Cardiovasc Disord 2004:4:5.

10. Rosendaal FR, Cannegieter SC, van der Meer FJ, Briet E. A method to determine the optimal intensity of oral anticoagulant therapy. Thromb Haemost 1993;29:236-9.

11. Diggle PJ, Liang KY, Zeger SL. Analysis of longitudinal data. New York: Oxford University Press; 1996.

12. Barry MJ, Cherkin DC, Chang Y, Fowler F, Skates S. A randomized trial of a multimedia shared decision-making program for men facing a treatment decision for benign prostatic hyperplasia. Dis Manag Clin Outcomes 1997;1:5-14.

13. Bernstein SJ, Skarupski KA, Grayson CE, Starling MR, Bates ER, Eagle KA. A randomized controlled trial of information-giving to patients referred for coronary angiography: effects on outcomes of care. Health Expect 1998;1:50-61.

14. Dunn RA, Shenouda PE, Martin DR, Schultz AJ. Videotape increases parent knowledge about poliovirus vaccines and choices of polio vaccination schedules. Pediatrics 1998;102:e26.

15. Green MJ, Biesecker BB, McInerney AM, Mauger D, Fost N. An interactive computer program can effectively educate patients about genetic testing for breast cancer susceptibility. Am 7 Med Genet 2001;103:16-23.

16. Lerman C, Biesecker B, Benkendorf JL, Kerner J, Gomez-Caminero A, Hughes C, et al. Controlled trial of pretest education approaches to enhance informed decision-making for BRCA1 gene testing. 7 Natl Cancer Inst 1997; 89:148-57.

17. Man-Son-Hing M, Laupacis A, O'Connor A, Biggs J, Drake E, Yetisir E, et al A patient decision aid regarding antithrombotic therapy for stroke prevention in atrial fibrillation. A randomized controlled trial. $7 A M A$ 1999;282:737-43.

18. Morgan MW, Deber RB, Llewellyn-Thomas HA, Gladstone P, Cusimano RJ, O'Rourke K, et al. Randomized, controlled trial of an interactive videodisc decision aid for patients with ischemic heart disease. 7 Gen Intern Med 2000;15:685-99.
19. Schwartz MD, Benkendorf J, Lerman C, Isaacs C, Ryan-Robertson A, Johnson L. Impact of educational print materials on knowledge, attitudes, and interest in BRCA1/BRCA2: testing among Ashkenazi Jewish women. Cancer 2001;92:932-40

20. Volk RJ, Cass AR, Spann SJ. A randomized controlled trial of shared decision making for prostate cancer screening. Arch Fam Med 1999;8:333-40.

21. Davison BJ, Kirk P, Degner LF, Hassard TH. Information and patient participation in screening for prostate cancer. Patient Educ Couns 1999;37:255-63.

22. Dolan JG, Frisina S. Randomized controlled trial of a patient decision aid for colorectal cancer screening. Med Decis Making 2002;22:125-39.

23. Murray E, Davis H, Tai SS, Coulter A, Gray A, Haines A. Randomized controlled trial of an interactive multimedia decision aid on benign prostatic hypertrophy in primary care. BM7 2001;323:493-6.

24. Clancy CM, Cebul RD, Williams SV. Guiding individual decisions: a randomized, controlled trial of decision analysis. Am 7 Med 1988;84:283-8.

25. Murray E, Davis H, Tai SS, Coulter A, Gray A, Haines A. Randomized controlled trial of an interactive multimedia decision aid on hormone replacement therapy in primary care. BMF 2001;323:490-3.

26. Wilson SJA, Wells PS, Kovacs MJ, Lewis GM, Martin J, Burton E, et al. Comparing the quality of oral anticoagulant management by anticoagulation clinics and by family physicians: a randomized controlled trial. CMA7 2003, 169(4):293-8.

27. Majumdar SR, Lipton HL, Soumerai SB. Chapter 30: Evaluating and improving physician prescribing. In: Strom B, editor. Pharmacoepidemiology. 4th edition. Toronto: John Wiley and Sons; 2005. p. 419-38.

28. Thomson R, Parkin D, Eccles M, Sudlow M, Robinson A. Decision analysis and guidelines for anticoagulant therapy to prevent strokes in patients with atrial fibrillation. Lancet 2000;355:956-62.

Correspondence to: Dr. Finlay A. McAlister, 2E3.24 Walter

Mackenzie Health Sciences Centre, University of Alberta

Hospital, 8440112 St., Edmonton AB T6G 2R7;

fax 780 407-2680; Finlay.McAlister@ualberta.ca

The DAAFI Investigators are: Steering Committee (unpaid):

Finlay A. McAlister, Malcolm Man-Son-Hing; External

Consultants (unpaid): David Sackett, Koon Teo,

Andreas Laupacis; Central Coordinating Office: Miriam Fradette

Paula Priest, Tammy Bungard, Ruth Dupuit, Marilou Hervas-

Malou, Sandra Blitz, Betty Larson, Sumit R. Majumdar.

\section{Holiday Review 2005 Call for submissions}

Hilarity and good humour ... help enormously in both the study and the practice of medicine ... [I]t is an unpardonable sin to go about among patients with a long face.

- William Osler

Yes, that's right, it's already time to send us your creative contributions for CMAJ's Holiday Review 2005. We're looking for humour, spoofs, personal reflections, history of medicine, off-beat scientific explorations and postcards from the edge of medicine.

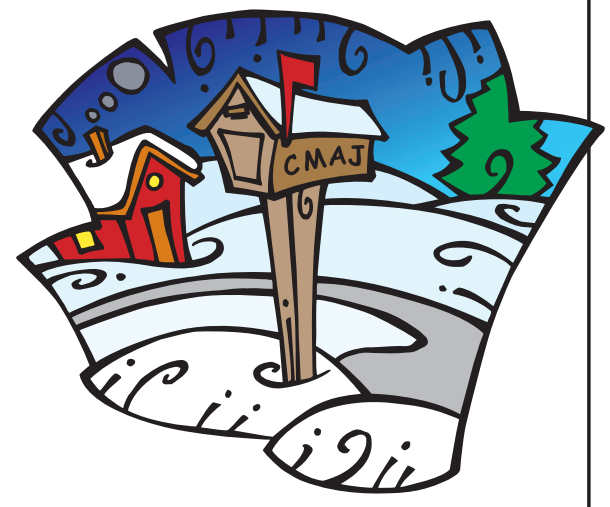

Send your offerings through our online manuscript tracking system (http://mc.manuscriptcentral.com/cmaj). Articles should be no more than 1200 words; photographs and illustrations are welcome. Please mention in your cover letter that your submission is intended for this year's Holiday Review.

The deadline for submissions is Sept. 20, 2005. 